\title{
TECHNICAL PRESENTATIONS: TO ENLIGHTEN OR OBSCURE
}

by Errol N. Nelson

Wilsey and Ham, Inc.,

Tukwila, Washington

Each year there are hundreds of technical society meetings which collectively present thousands of papers specifying the advances in a given technology in a brief and concise fashion. Each year, out of the thousands of papers presented only a small percentage will stimulate the audience. The rest will be received with an "Oh, that's interesting!" or "Humm!" and be quickly relegated to the recesses of the mind. The cause will be not that the subject wasn't interesting or informative but that the presentation was so poorly given that it was incomprehensible to the audience.

Why is it that technical society meetings and conventions are resigned to having authors present their papers in a dull and boring manner? It is well known that the majority of scientists, engineers, and technologists attend conventions to renew friendships and talk with colleagues about their work on a one to one basis, rather than listen to the presentation of papers. This leaves the younger members, who know very few people, to attend the technical sessions and to be indoctrinated into a self perpetuating system that will influence the quality of papers they will be presenting in a few years. Even then, there are many papers with interesting titles or abstracts, and many attend in the vain hope they can decipher the jargon and figure out what the author was trying to say. Usually they are disappointed because the presentation doesn't make much sense.

Technical societies usually demand quality in their journal articles. However, these same organizations do not require, nor do they receive, similar quality in oral presentations of these articles. Why don't technical societies demand, and get, oral presentations that are comprehensible to a multidisciplinary audience?

This inability to communicate effectively often carries over to the public sector giving the impression that science is beyond the understanding of the average individual and that scientists have their heads in the clouds and are not concerned with the realities of life. Scientists, in actuality, may be concerned, but the message they convey appears to contradict this. The effect of this communications gap with the public is an impression that advances in technology are to be feared and fought down with little or no consideration given to the potential benefits that may occur.

What is the cause of this sorry state of affairs? The basic purpose of any presentation, written or oral, technical or otherwise, is to communicate and to share information, knowledge, or opinions with others. The author wants to convince the audience the subject is worthwhile and the results are valid. The audience want the information to further their knowledge of the subject. If this purpose is not accomplished what is the sense in making a presentation? For example: the purpose of this 
paper is to explain to technical personnel methods for improving oral presentations so they may communicate better and in a more interesting fashion with their colleagues and the general public.

There are two primary reasons for poor oral presentations. First, the format and style required of technical papers does not lend itself to effective oral presentation. Second, many speakers suffer from severe stage fright and rush through their papers to end their misery as soon as possible. The combination of the two is devastating and can, and often does, result in the presentation of complete nonsense. What can technical societies, and individual authors do to improve the quality of oral presentations?

\section{Technical Papers}

There are some major differences between writing a technical paper and making an oral presentation of the same material. In writing, the attempt to achieve a good style of presentation requires that two important influences must be overcome. First, the journals plead for comprehension and brevity, and second, custom requires the authors to write impersonally. ${ }^{1}$ For example: The APCA Guide for Authors ${ }^{2}$ specifies that an author "Assume the reader is not a novice in the field. Give essential information in a concise fashion. Avoid wordiness, duplication, and unnecessary detail. Include only as much history as is needed to provide background for the particular material covered in the paper." This is a direct requirement that the paper be short and to the point with no extraneous material cluttering it up.

As the author tries to conform to the impersonal approach a more or less deformed style inevitably develops. Although the author has been the chief actor in the drama, on stage from the beginning of the research, when he presents the work to the public he usually follows the prevailing custom and tries to become invisible. The unnatural contortions he must undergo in the attempt can scarcely produce a relaxed style. ${ }^{1}$

Technical requirements also dictate that the author refrain from using the word "I" to sustain the fiction of impersonality. This, in effect, encourages the use of a passive voice and almost every statement is qualified. The result is a vague, ambiguous paper where, the results can be easily misinterpreted. Please note: I also must follow the prevailing custom in this paper and write in the third person, impersonal style to conform to requirements. This paper is totally unsuitable for an oral presentation.

The fiction of impersonality also spawns the comparison that science is similar to spectator sports, "....... in which the scientist is a spectator. He has no voice, no opinions, and everything is observed from a detached point of view. Ideally, he also doesn't care who wins." 3 How can an individual experience an event and then present it as if he were not involved? Only with great difficulty. However, this is what is expected of scientists - zealous uninvolvement - both in their work and in the presentations of the results. 
An additional underlying factor in the publication of some papers is a manifestation of the "publish or perish" syndrome. Adherence, especially by colleges and universities, to the premise that professional advancement is contingent upon the number of papers published, or presented at the appropriate technical society meetings, leads to a proliferation of largely irrelevant information. The governing criterion is quantity of output, not quality. The result is, that minor aspects of experiments or events are seized upon and amplified into full blown articles, not truly to inform, but to fulfill the demand of the "publish or perish" doctrine. The ramifications of this doctrine are obvious and can lead directly to the obscuration of information in order to prevent the revelation that the paper was based on inadequate or insufficient data.

The technique for written presentations often results in a brief, passive, detached paper where understanding is strained and interpretation is open to question. The methodology required for the written presentation of papers often only confuses an author when it comes to making the changes required to make an effective oral presentation.

\section{Oral Presentations}

The primary purpose of an oral presentation is to inform and/or provoke the interest of the audience sufficiently to entice them to pursue knowledgeably the subject in depth, if they wish. Good oral presentations are simple, direct, and to the point. 4,5 The main theme is repeated several times to reinforce it. The voice is modulated and gestures with the hands and body are utilized to convey emphasis.

It is almost impossible to take a paper written in a brief impersonal style, where the information is provided only once, and read it directly to an audience. Reading the text verbatim merely makes communication more difficult. Reading the paper aloud to an audience is analogous to silently reading one of Shakespeare's plays. Silently reading the play does not provide the impact nor the drama conveyed by the spoken word accompanied by appropriate gestures and voice emphasis. An author who reads his paper is doing the audience a disservice. If the complete text of the paper is provided, an interested individual can obtain it and take all the time he wants to comprehend it. However, with the fees currently being levied on preprints ( $\$ 1.00 /$ copy) this can become expensive. To read a paper without any interpretation or feeling for what is being presented is a major contributor to making technical presentations dull and boring. The main purpose is to communicate knowledge and information, not to read the paper just to get it over with.

\section{Problems in Preparing the Oral Presentation}

The major problems confronting the author's oral presentation are the method of delivery; how and what is going to be discussed; in what order; and what should be emphasized. The biggest hurdle to overcome is trying to fix complex subject matter into a 15-20 minute time frame, especially if there are numerous graphs and tables. The technical paper gets the data, tables, and graphs "on the record", but this information cannot be orally presented in its entirety in an adequate manner. There is insufficient time, even with slides, to detail this information orally. 
Therefore, the majority of the data must, of necessity, be clarified in summary form.

It is unlikely that the technical journals are going to change their formats to accommodate a different style of expression. Therefore, it becomes incumbent on the author to make the appropriate changes for his oral presentation so that the paper is delivered in a comprehensible fashion. At this point the author is confronted with two problems. What is he going to extract from his paper and how is he going to deliver it within the alloted time frame of 15-20 minutes normally given for such presentations. Although the paper may not be the same as the oral presentation they still have the same general format (i.e. an introductory section, a body, and the presentation of results and conclusions.) This format provides the basis for both the written paper and oral presentations. Many oral presentations suffer because with this format, the material is all there but there is no structure. As a result the author never quite gets around to explaining the purpose of the paper.

It is not possible realistically to fit a standard length paper (3-5 journal pages, averaging 7-10 tables and graphs) into the allotted 15-20 minutes. Therefore, it becomes necessary to indentify precisely what is to be said. Examine the paper, the introduction, the body, and the conclusion and write in one sentence the point that is to be made. Ideally, the sentence should be included in the abstract. Everything given in the oral presentation will revolve around this basic theme. For example, the purpose of this paper is to explain to technical personnel methods for improving oral presentations so that they may communicate better and in a more interesting fashion with their colleagues and the general public.

All that now remains is to take the main theme, fill it in with details from the paper, and talk about it for 20 minutes. Right? Not so! There is nothing quite so subjective as a speech, regardless of the material, because the author is directly involved in its presentation. Unlike a journal paper it cannot be approached in the same detached fashion. The attempt to approach an oral presentation with "uninvolved" objectivity and detachment is the reason many papers are dull and boring. Here is where the author must add his own personal stamp to the paper, because for better or worse, it's all his and nobody else's. Hiding behind the fiction of the third person approach is impossible in an oral presentation. The third person approach has long been an excuse for not taking the responsibility for statements in case the results or conclusions are erroneous - the epitome of the don't get involved spectator. However, up on the dias speaking to an audience there is no escaping the responsibility of involvement in the paper. To attempt it often results in gibberish, even though it sounds like English. If the data and conclusions cannot stand up under the author's own scrutiny, what credibility can it be expected to have for others?

Problems in Delivering the Oral Presentation

A major reason for technical papers being dull and boring is the sudden realization by the author that by standing in front of an audience he can no longer "hide" his personal involvement. This thought strikes 
unreasoning fear in many otherwise intelligent and articulate men and women. The very idea of speaking in front of an audience is so frightening that some people would rather do anything else. Its contribution to obscuring technical presentations is incalculable. Fear is one of the strongest of emotions and alleviating it is no easy task.

Fear often manifests itself in the lack of enthusiasm of the author. The paper is given in a monotone with no voice fluctuation or other involvement. Many potentially good papers suffer because of fear on the part of the author. Many technical papers are read verbatim out of fear that paraphrasing will create false impressions and magnify mistakes. Many authors fear speaking in public because they think they will look, or be made to look, foolish. Others assume that unless they are witty, urbane, and articulate, the speech will not be interesting so they compensate by reading most of the paper. The result is that the paper is not interesting and their expectations become a self fulfilling prophecy. This need not be so!

\section{From Paper to Presentation}

Speakers have devices available to them that are not conveyed by the written word. The oral presentation should inform and interest the audience sufficiently to satisfy their curiosity or provoke them to pursue the subject further.

\section{Preparation}

The material used in the oral presentation is already available in the written paper. However, it must be converted to a different format to convey the proper message to the audience. The primary emphasis must be on the purpose of the paper. Here is where the one sentence abstract comes into play. Support this theme by illustrating how the approach leads to the solution and how the data confirm, or deny, what was accomplished. In preparing an oral presentation an apt description of the three parts of a speech and what each should accomplish is: "In the introduction, tell the audience what you are going to say. In the body, say to the audience what you are going to say. In the conclusion, tell the audience what you have said." Using this concept the theme is repeated at least three times. Each repetition reinforces to the audience the purpose of the presentation.

\section{Delivery}

Delivery of an oral presentation will be dictated by two factors. First, the composition of the audience will determine the language used. Second, the use of voice emphasis and gestures will amplify the major point of the presentation.

Knowing the audience will determine the complexity of the language in the presentation. It is of no use to use jargon on an audience where the majority has never heard the terminology. This is especially true in an organization like APCA, with its multidisciplinary requirements. Technical professions have a tendency to use jargon, or language peculiar to an individual profession, to add an aura of competence and mystery to 
their presentation. In a multidisciplinary field such as air pollution, jargon can work against the presentation as much as for it. The net result is difficult to comprehend, especially by those individuals who do not have a working familiarity with the field. We have all seen examples of individuals who use jargon or seldom used language to impress an audience. They usually confuse, however, instead of impressing. I call such people pleonastic sesquipedalians, or more simply, pompous windbags .

The most effective speakers keep their language simple and to the point. It is difficult to imagine a famous orator such as Franklin D. Roosevelt or Winston Churchill using language that does not convey his message in the simplest possible terms. The presentation, to be effective, must leave an impression of understanding, otherwise it will leave the audience disappointed and confused. Being precise is fine, but one can be so precise that the only thing lacking is understanding. The speaker must adapt his speech to the audience, not vice versa.

The majority of "sins" committed during a presentation go unnoticed by the audience. A primary worry of many speakers, more imaginary than real, is the sin of omission. The speaker is afraid he might leave something out so he stutters, stammers, and repeats himself. If something is left out, who is going to know. No one is going to jump up and say something was excluded.

Usually, any omission, which is mostly detailed amplification of a major point in the body of the presentation, may leave a small hole in its continuity but most people will assume that omissions are made because of time restrictions. By way of analogy, Julia Child on the French Chef television program was cooking a chicken. While carving the chicken in the kitchen, she pushed too hard with the knife and it landed on the floor. One would naturally assume that the meal was ruined. However, she put the chicken back on the counter and resumed carving with the statement - "If you don't tell them, how are they going to know." The chicken was subsequently served as if nothing had happened. In speaking, if omissions are made in the text no one will know, especially if it is being paraphrased. The audience will only assume that some details must be eliminated to fit the time frame required for presentation. An omission will only become obvious if a major point is left out and appears from nowhere later in the presentation.

A second sin, usually committed by inexperienced speakers, is trying to fill up the speaking time with words. Sentences and paragraphs melt into one continuous monotonic discourse with no emphasis on the importance of the various points that are being made. Yet, the pause is one of the most effective tools the speaker has in repertoire. By pausing, three things are accomplished. First, the speaker can catch his breath and quickly glance ahead in his notes. Second, he can allow an important point to sink in to the audience so that both know that a major point or break has been made in the presentation. Third, he can observe the reaction of the audience to what has been said. Thus, refreshed, he can continue on to the next point. 
Technical journals, with their penchant for brevity, loathe repetition. Conversely, the basis of a good oral presentation is selective repetition, reinforcing the main themes and emphasizing the major points.

\section{Visual Aids}

The use of visual aids can be a help or lend to the confusion depending on how they are used. Maps, photos, charts, graphs, and tables are the most frequently used visual aids. However, it must be understood that it usually takes from 1 to 4 minutes to explain adequately each visual aid in an oral presentation. This limits the number of slides that can be effectively presented. It is not sufficient to say that this chart explains this point and go on. It must be on the screen long enough for the values to sink in and mean something to members of the audience. Moving quickly from one slide to another is confusing and frustrating to someone who is trying to determine the trend of the information for himself. Maps and pictures are of immeasurable aid in identifying or 1ocating the site of an experiment. Photos of equipment, on location, allow the audience to identify the conditions under which the experiment occurred and provide an image and understanding not quickly conveyed by verbal methods.

The presentation of tables, charts, or graphs creates the most problems with visual aids. Of these, tables are the most difficult to comprehend. The display of large quantities of numbers on a screen usually requires a substantial period of time for the audience to absorb, even with the help of the speaker. Charts and graphs, with their bars and lines, visually allow instant comparison by the audience, increasing the likelihood of comprehension in a shorter time period.

To keep visual aids, both in papers and oral presentations, in perspective the information any one aid presents must be limited. The American Chemical Society Handbook for Authors ${ }^{6}$ limits the number of lines on any one graph to four. If this limitation applies to a paper where the graph can be studied at length it must be doubly emphasized on a slide that is shown for a short period of time. To overcome this deficiency in a positive manner, the PNWIS Section of APCA gives an annual presentation at its local section meeting called the "Happy Looker Award". It is given to the individual who makes the most effective use of visual aids. Perhaps APCA should establish guidelines on the use of visual aids for meeting papers, placing limits on the number of values or lines that any one table or graph may contain.

\section{Getting Started}

The most difficult part of any oral presentation comes in the introduction and involves getting the attention of the audience. By that I mean that the audience has been adequately briefed on what you are going to say in the rest of the presentation and is receptive to hearing additional information. This can be accomplished several ways. One way is to find a theme, another way is to ask a question directed at the purpose of the paper. The author can also present the main conclusion of the paper and use the rest of the presentation to support that conclusion. A 
fourth way, is to say something controversial and then use the rest of the time to confirm or deny the contention. The controversy may be speculation but the idea is to get the attention of the audience.

One way often tried, but not usually successful, is to tell a joke or amusing story. This is a difficult approach because jokes have a way of falling flat unless they are properly told. Ideally, any joke or story should relate to the rest of the paper; otherwise 1-2 minutes have been wasted on an irrelevant item. Stories, amusing or otherwise, relating to events that happened involving the paper are good because they present the human side of technology. The audience knows that the data just don't arrive to be presented in the finished form, but it helps to relate some event or incident that helped shape the paper.

\section{Conclusion}

The presentation of technical material can be made comprehensible. The only requirements to making an effective speech are to know your audience, know your subject and precisely what you are going to say. Keep it in simple language picking out the highlights and don't be afraid that something will be left out. The main purpose of any presentation, written or oral, is to communicate. If the subject is not communicated in a manner that is understood, then the purpose of the paper has been lost. Hopefully, if the suggestions are followed we can have technical papers that enlighten, not obscure.

\section{REFERENCES}

1. MENZEL, D.H., JONES, H.M. and BOYD, L.G., Writing a Technical Paper. McGraw Hill Book Company, New York, 1961.

2. "APCA Guide for Authors", Air Pollution Control Association, Pittsburgh, 1976 .

3. MASLOW, A.H., The Psychology of Science - A Reconnaissance, Henry Regnery Company, Chicago, 1966.

4. "Communication and Leadership Program", Toastmasters International, Santa Ana, 1970.

5. SHEFTER, H., How to Prepare Talks and Oral Reports, Pocket Books, New York, 1963.

6. "Handbook for Authors", American Chemical Society, Washington, DC, 1967 . 